\title{
Correlation between the Size of Tumour with Early Postoperative Serum Sodium Imbalance in Sellar and Suprasellar Space Occupying Lesion after Transsphenoidal surgery

\author{
Hossain $\mathrm{MM}^{1}$, Kadir $\mathrm{ML}^{2}$, Jahan $\mathrm{NA}^{3}$, Hasan $\mathrm{MM}^{4}$, Uddin $\mathrm{KH}^{5}$, Saha $\mathrm{MK}^{6}$, Hafiz $\mathrm{AM}^{7}$, Barua $\mathrm{KK}^{8}$
}

Conflict of interest: There is no conflict of interest relevant to this paper to disclose.

Funding Agency: was not funded by any institute or any group.

Contribution of Authors: Principal Investigator and Manuscript preparationData collection-

Scalp block with anaesthesia-

Editorial formatting-

Copyright: @2020bang.BJNS published by BSNS. This article is published under the creative commons CC-BY-NC license. This license permits use distribution (https://creativecommons. orgf/licences/by-nc/4-0/)reproduction in any medium, provided the original work is properly cited and is not used for commercial purposes.

Received: 12.03 .19

Accepted: 01.07.19

\begin{abstract}
Background: Seller and suprasellar space occupying lesions are frequently encountered intracranial lesions now-a-days. Surgery through transsphenoidal route is the most preferable approach which is frequently performed for excision of these space occupying lesions. The lesions are located in a very critical area because they are surrounded by the hypothalamus, pituitary gland and cavernous sinus which are responsible to maintain various hormonal functions as well as regulation of plasma osmolality and plasma electrolytes. So, during and after operation various types of osmolality and electrolytes related complications are often encountered. Among them serum sodium imbalance is the most frequent one.
\end{abstract}

Objective: Tumour size is one of the very important predisposing factors which influence the serum sodium level after surgery. For investigating the correlation between the size of sellar and suprasellar space occupying lesions with the incidence of postoperative sodium imbalance after transsphenoidal surgery of the patient having these lesions.

Material and method: Thirty patients with sellar and suprasellar space occupying lesions meeting the inclusion criteria were enrolled. The largest diameter of the tumour was measured in the coronal or sagittal planes from pre-operative MRI's. They underwent transsphenoidal surgery and were observed for first 7 postoperative days and serum electrolytes was measured every day. Patients in this study were considered to have serum sodium imbalance if the narrow range of $135-145 \mathrm{mmol} / \mathrm{L}$ was not maintained. Then according to the tumour size they were divided in to two groups. Then the two groups were compared and the frequency of development of post-operative sodium imbalance, their time of onset and types of imbalances were observed.

Result: $60 \%$ of the patients in our study developed post operative serum sodium imbalance after transsphenoidal surgery. Among them 40\% of the patients developed hypernatraemia, $13.3 \%$ of the patient developed hyponatraemia and only $6.7 \%$ patient developed combined imbalance. Hypernatraemia is more common than hyponatraemia after transsphenoidal surgery. Peak incidence of hyponatraemia occurred on 3rd post-operative day and hypernatraemia occurred at 1st postoperative day. In the large size tumour group (>30mm) $46.66 \%$ had serum sodium imbalance and imbalance was observed in $13.33 \%$ of the small size group $(d " 30 \mathrm{~mm})$ and there is significant difference of sodium imbalance between large and small size group and p-value was 0.001. $r$-value 0.776 indicates that the size of the tumour strongly correlates with postoperative sodium imbalance and there is significant association between size of

1. Dr. Muhammad Mahabub Hossain, Assistant Professor Neurosurgery, Sir Salimullah Medical College and Mitford Hospital, Dhaka, Bangladesh.

2. Dr. Md. Lylatul Kadir, Assistant Professor Neurosurgery, Rajshahi Medical College and Hospital, Rajshahi, Bangladesh.

3. Dr. Naznin Akter Jahan, Assistant Professor, Biochemistry, National Institute of Preventive and Social medicine, Mohakhali, Dhaka.

4. Dr. Md. Motasimul Hasan, Assistant Professor Neurosurgery, Dhaka Medical College.

5. Dr. Kazi Hafiz Uddin, Assistant Professor Neurosurgery. NINS

6. Dr. Milton Kumer Saha, Assistant Professor Neurosurgery. SZMC, Bogura.

7. Dr. Ahsan Mohammed Hafiz, Assistant Professor department of Neurosurgery, Uttara Adhunik medical college and hospital

8. Professor Kanak Kanti Barua, Vice Chancellor, Bangabandhu Sheikh Mujib Medical University, Dhaka

Address of Correspondence: Dr. Muhammad Mahabub Hossain, Assistant Professor Neurosurgery, Sir Salimullah Medical College and Mitford Hospital, Dhaka, Bangladesh. Mob:01712082325, E-mail: mahabubmmc33@gmail.com 
the tumour with sodium imbalance. The study found no significant association between age, sex or types of the lesions with postoperative sodium imbalance ( $p=0.43)$.

Conclusion: Post operative serum sodium imbalance after transsphenoidal surgery is a burning issue for the neurosurgeon now a day. Early prediction of these types of notorious complication is helpful for preoperative and post operative management of the patient. The size of the lesion is one of the most significant markers. As well as a strong association between size of the tumour with post operative sodium imbalance was found. This will help us in perioperative management of the patients, and reduces complication related mortality and morbidity after the transsphenoidal surgery.

Key wards: Tumour, early postoperative, serum sodium imbalance, sellar and suprasellar, space occupying lesion, transsphenoidal surgery.

Bang. J Neurosurgery 2020; 10(1): 82-91

\section{Introduction:}

The sella turcica lies in close proximity to several important anatomical structures including the optic chiasm, the internal carotid arteries and the pituitary gland, which is connected to the hypothalamus ${ }^{1}$. The pituitary gland is enclosed in the sella turcica and bridged over by a fold of duramater called the diaphragm sellae, with the sphenoidal air sinuses below and the optic chiasm above. The cavernous sinuses are lateral to the pituitary fossa and contain the $3^{\text {rd }}, 4^{\text {th }}$, Va and 6 th cranial nerves and the internal carotid arteries. The gland is composed of two lobes, anterior and posterior, and is connected to the hypothalamus by the infundibular stalk, which has portal vessels carrying blood from the median eminence of the hypothalamus to the anterior lobe and nerve fibers to the posterior lobe ${ }^{2}$.

Diseases of the hypothalamus and pituitary are rare, with an annual incidence of approximately 1:50000². Lesions of the sellar and parasellar region are very common, accounting for $10-15 \%$ of intracranial masses based on surgical experience. Pituitary adenomas account for about $90 \%$ of lesions of the sellar and parasellar region according to different large surgical series ${ }^{3}$.

A sellar mass was diagnosed in 1197 patients undergoing MRI. Pituitary adenomas accounted for $81 \%$ of all diagnosed masses, with most due to prolactinomas and nonfunctioning adenomas. Rare cases of a functioning TSH adenoma, functioning $\mathrm{LH} /$ FSH adenoma, and other mixed hormone producing adenomas were also observed. Two hundred sixteen pituitary masses identified by MRI were not adenomas, accounting for $18 \%$ of all observed lesions. One hundred twenty-four of these masses were newly diagnosed after pituitary MRI scans and confirmed with pathological reports. The most common etiology encountered in this group was a pituitary cyst, with Rathke cleft cyst representing $19 \%$ of all nonadenomatous lesions. Other commonly observed masses were craniopharyngiomas $(15 \%)$ and meningiomas $(15 \%)^{4}$.

Sellar and suprasellar masses occur with overlapping clinical and radiological features, ranging from asymptomatic incidental presentations to hormonal symptoms, or compressive local mass effects on nearby vital surrounding structures. The severity depends on the location, size and growth potential of the tumour ${ }^{3}$.

Common clinical picture, due to mass effect of expanding tumor impinging on neighbor structures: visual defects (from minimal visual field defect to typical hemianopsia to amaurosys), headache, and symptoms of hyper and hypopituitarism. Giant adenomas can give rise to cavernous sinus syndrome with oculomotor nerve palsies or seizures (when expanding through cavernous sinus to temporal lobe), DI, SIADH and hydrocephalus. These latter manifestations are so rare that must prompt an accurate differential diagnosis with non-adenomatous lesions of the region. All these entities, mostly Cushing's disease and acromegaly, are associated to increased morbidity and mortality, when untreated. Although commonly defined as benign tumors, invasion of surrounding tissues can occur in half of pituitary adenomas $^{3}$.

$\mathrm{ADH}$ (vasopressin) which is secreted from posterior pituitary has physiological effects on collecting duct of kidney resulted increase the permeability of collecting duct and reabsoprtion of water through water channel (aquaporin) by binding with $\mathrm{V} 2$ receptor in the process of simple diffusion. It is one of the important hormones who maintain the sodium and water homeostasis in the body ${ }^{5}$. 
The perfect surgical routes to the sellar and suprasellar lesions from below are through transsphenoidal approaches or from above subfrontal or pterional transsylvian approach or basal bifrontal interhemispheric approach. The two main lines of approach to sella turcica and pituitary gland the high way (transcranial) and the subway (transsphenoidal) were being developed in early 1900 . The selection of surgical approach is based on size of the tumour and its anatomical extension. Proper selection of the surgical approaches and extent of resection has got tremendous influence upon mortality, morbidity or progression free survival ${ }^{6}$.

Mechanism causing hypopituitarism in large pituitary adenomas may be infundibular compression and the resulting impaired delivery of hypothalamic hormones, rather than destruction of the pituitary tissue by the tumour. This explains the better recovery rate of pituitary function in cases with preoperative hyperprolactinemia ${ }^{7}$.

After transsphenoidal surgery, DI can results from an interruption in the transport of ADH release from the posterior pituitary, or retrograde damage to the cell body in the hypothalamic nuclei. Thus damage anywhere along the hypothalamus pituitary axis can result $D I^{8}$. Following transphenoidal surgery $\mathrm{DI}$ and SIADH may cause morbidity due to fluid and electrolyte imbalance and in particular disturbance of sodium homeostasis due to inappropriate antidiuretic hormone secretion ${ }^{9}$.

Because sodium is the main constituent of plasma osmolality, these osmolality related disorders (DI and SIADH) are typically characterized by hypernatremia and hyponatremia, respectively ${ }^{10}$. Hypernatraemia is more common than hyponatraemia after transsphenoidal surgery. Recent study showed that $35 \%$ patients developed hypernatraemia ( $\mathrm{Na}>145$ $\mathrm{mmol} / \mathrm{L}$ ) with peak sodium levels at a median of 2 days (mean 2.3 days) following surgery and 18\% patients developed hyponatraemia ( $\mathrm{Na}<135 \mathrm{mmol} / \mathrm{L}$ ) with sodium levels at a median of 6 days (mean 6.4 days) postoperative ${ }^{1}$.

While most changes are mild, symptoms can occur if the serum sodium level falls below $130 \mathrm{mmol} / \mathrm{L}$ or above $149 \mathrm{mmol} / \mathrm{L}$. The condition is transient in the majority of cases, although the incidence of prolonged or permanent $\mathrm{DI}$, as a result of a more central injury of the pituitary-hypothalamic region, has been reported to range from 1.6 to $31 \% 4$.
In case of insufficient ADH secretion, high quantities of dilute urine can be lost and the serum sodium level and plasma osmolality may raise leading to the need for water replacement. In case of inappropriate or uncontrolled $A D H$ release (not stimulated by increased plasma osmolality or hypovolemia; but triggered by brain signals or caused by neuronal damage), serum sodium usually drops unless water supply is markedly restricted $^{9}$. Symptoms of sodium imbalance include dizziness, headaches, paraesthesias, nausea, vomiting and lethargy, but can progress to altered mental status and seizures if severe hyponatraemia or hypernatraemia occur ${ }^{11}$.

SIADH may occur after surgical manipulation of the pituitary stalk, neurohypophysis or the hypothalamus. However, a recent meta-analysis found that postsurgical DI was less frequent in those who underwent endoscopic surgery compared to those who had microsurgical resection $(15 \%$ vs. $28 \%, p=$ $0.03)^{12}$.

The following variables: age, diagnosis, extension (intrasellar and extrasellar), sex, tumour size (macroadenoma, microadenoma and giant adenoma) may influence the postoperative sodium imbalance. Tumour size was of significance for the development of hyponatraemia ${ }^{13}$. Previous studies have suggested the tumor size or patient age as risk factors for postoperative hyponatremia after pituitary surgery ${ }^{1}$ (Staiger et al., 2013). Previous study found no impact of sex on the incidence of postoperative DI or hyponatremia ${ }^{13}$.

The incidence of a plasma sodium disturbance was $61 \%$ in the group with larger tumours and $43 \%$ in the small group. This supports the findings of an earlier study, which stated that patients with macroadenomas are more at risk to develop delayed hyponatraemia than patients with smaller tumour ${ }^{1}$.

Some authors have shown DI is more common after the resection of macroadenoma the circumstance is likely caused by the more aggressive gland and stalk manipulation required during resection of tumour as well as changes in sellar and suprasellar anatomy ${ }^{8}$. A study that identified lesion size as a risk factor for postoperative hyponatremia could reflect the fact that larger lesions require manipulation of the pituitary stalk for resection ${ }^{14}$.

The purpose of this study is therefore to assess whether prognostic factor (tumor size) has any association with postoperative sodium imbalance or not. 
Methods and materials

This cross- sectional analytical study was carried out in the Department of Neurosurgery, Bangabandhu Sheikh Mujib Medical University and some private hospitals in Dhaka from July 2013 to December 2014 Patients having seller and suprasellar SOL and plan to undergo transsphenoidal surgery for the first time. Purposive and convenient sampling technique was used. The sample size was 30 . Sample was divided into two groups. In Group 1: Tumor diameter $>30 \mathrm{~mm}$ and in Group II: Tumor diameter d"30mm (The largest diameter of the tumor measured in the coronal or sagittal plane). The selection criteria was Patient having seller and suprasellar space occupying lesion (SOL) who have undergone transsphenoidal surgery for the first time. The exclusion criteria were patient having metabolic diseases e.g. CRF, Uncontrolled Diabetes mellitus and Cushing diseases, recurrent sellar and suprasellar tumour, plan to excision of the tumor through transcranial or combined approaches and patient who had preoperative sodium imbalance and postoperative diarrhea, vomiting and patients got diuretics. The variables were tumor size (The largest diameter of the tumor measured in the coronal or sagittal plane from preoperative MRI of the brain), Hyponatremia (measured by ISE method), Hypernatremia (measured by ISE method). Data were collected using a data collection sheet. On the basis of inclusion and exclusion criteria cases were selected from the neurosurgery department of proposed hospitals. All patients were explained about the nature and purpose of study and their informed written consent were obtained. Relevant baseline information were recorded in a preformed data collection sheet. After measuring the tumour size they were grouped in to two groups. Group I: tumour size $>30 \mathrm{~mm}$; group II -tumour size d" $30 \mathrm{~mm}$ (the largest diameter of the tumour measured in the coronal or sagittal plane). Then surgery was performed through transsphenoidal approach by different surgeons. Electrolytes level were measured daily for 7 days. Patients in this study were considered to have serum sodium imbalance if the narrow range of $135-145 \mathrm{mmol} / \mathrm{L}$ is not maintained. Then the two groups were compared regarding the frequency of development of post operative sodium imbalance, their time of onset and types of imbalance. Data were processed by utilizing IBM SPSS Statistics program (version 17.0). Results will be described in frequencies or percentages. In this study laboratory tests were done such as in preoperative state Serum electrolytes, Serum creatinine, Serum glucose level, Hormonal assay. In postoperative state Serum electrolytes ( $1^{\text {st }}-7^{\text {th }}$ post operative day) and Urinary specific gravity (measured by specific gravity meter) were measured as laboratory taste. Pre operative MRI scan brain was also studied. Data were processed by utilizing IBM SPSS Statistics program (version 17.0). Results were described in frequencies or percentage. Statistical comparisons were done using fisher's exact test, spearman rank correlation test and chi-square test. P-value d" 0.05 was considered statistically significant.

\section{Results:}

Of the 30 patients, the most common age of presentation were between $21-40$ and $31-40$ years $(26.7 \%)$ each. $20 \%$ were in $41-50$ age group years, $16.6 \%$ were d" 20 years, only $10 \%$ were $>50$ years . Maximum $73.4 \%$ were in between $21-50$ years. Mean age of the patients was $34.5 \pm 15.1$ years and lowest and highest ages were 8.5 and 70 years respectively. Shown in Table I

Table-I

Distribution of patients by age $(n=30)$

\begin{tabular}{lcc}
\hline Age & Frequency & Percentage \\
\hline$\leq 20$ & 5 & 16.6 \\
$21-30$ & 8 & 26.7 \\
$31-40$ & 8 & 26.7 \\
$41-50$ & 6 & 20.0 \\
$>50$ & 3 & 10.0 \\
Total & 30 & 100.0 \\
Mean \pm SD & $34.5 \pm 15.1(8.5-70)$ & \\
\hline
\end{tabular}

Distribution of the patients by gender $63.3 \%$ were males and only $36.7 \%$ were females, giving a male female ratio of roughly $1.72: 1$. Shown in table no. II

Table-II

Distribution of patients by Gender $(n=30)$

\begin{tabular}{lcc}
\hline Gender & Frequency & Percentage \\
\hline Male & 19 & 63.3 \\
Female & 11 & 36.7 \\
\hline Total & 30 & 100.0 \\
\hline
\end{tabular}

Distribution of patients by clinical feature. Headache was the most common clinical presentation, $100 \%$ of patients were presented with this feature. Next frequent feature was visual impairment $93.3 \%$. $33.3 \%$ of the patients presented with vomiting, $26.7 \%$ patients 
presented with cranial nerve palsy, 20\% patient presented with features of hyperpitutarism (eg. Acromegaly ) on other hand $13.3 \%$ of the patients were presented with feature of hypopituitarism (eg. Hypogonadism, hypothyroidism etc.) and only $10 \%$ patients had history seizure. Shown in Table No. III.

Table-III

Distribution of patients by clinical features

\begin{tabular}{lcc}
\hline Clinical features & Frequency & Percentage \\
\hline Vomiting & 10 & 33.3 \\
Headache & 30 & 100.0 \\
Seizure & 3 & 10.0 \\
Visual problem & 28 & 93.3 \\
$3^{\text {rd }}, 4^{\text {th }}, 5^{\text {th }} \& 6^{\text {th }}$ nerve palsy & 8 & 26.7 \\
Feature of hypopituitarism & 4 & 13.3 \\
Feature of hyperpitutarism & 6 & 20.0 \\
\hline
\end{tabular}

Among the 30 patients 15 had tumour size (maximum diameter in coronal or sagittal plan of MRI) were d" $30 \mathrm{~mm}$ and the other 15 had tumour size were $>30 \mathrm{~mm}$. The range of size was $15-53 \mathrm{~mm}$. Mean size of the tumour was 32.3. Shown in table No. IV.

Table-IV

Distribution of patients by size of lesions $(n=30)$

\begin{tabular}{lcc}
\hline Size of lesion $(\mathrm{mm})$ & Frequency & Percentage \\
\hline $\mathrm{d}$ " 30 & 15 & 50.0 \\
$>30$ & 15 & 50.0 \\
Total & 30 & 100.0 \\
Mean \pm SD & $32.3 \pm 11.9(15-53)$ \\
\hline
\end{tabular}

Distribution of patients according to the sites and extension of the lesions. Sellar tumours with suprasellar extension were the most frequently encountered which accounted $76.7 \%$ of all lesions. Only $10 \%$ patients had the lesions located in pure supra sellar region and $13.3 \%$ patients' lesions remain only in sellar region. Shown in Table No. V.

\section{Table-V}

Distribution of patients by lesions according to their sites and extension of lesions $(n=30)$

\begin{tabular}{lcc}
\hline Type of lesion & Frequency & Percentage \\
\hline Sellar & 4 & 13.3 \\
Supra Sellar & 3 & 10.0 \\
Both & 23 & 76.7 \\
\hline Total & 30 & 100.0 \\
\hline
\end{tabular}

Distribution of patients by type of approach. Resection through Trans nasal endoscopic rout was done on $56.7 \%$ of patients $33.3 \%$ of patients underwent surgery through Transnasal microscopic approach. Sublabial microscopic approach was implicated on $10 \%$ of patients. Shown in table No. VI.

Table-VI

Distribution of patients by approach of surgery $(n=30)$

\begin{tabular}{lcc}
\hline Approach of the surgery & Frequency & Percentage \\
\hline Trans nasal microscopic & 10 & 33.3 \\
Sublabial & 3 & 10.0 \\
Trans nasal endoscopic & 17 & 56.7 \\
\hline Total & 30 & 100.0 \\
\hline
\end{tabular}

Table VII shows that $18(60 \%)$ of the patients developed serum sodium imbalance. Among them $40 \%$ had hypernatremia (11 pts. $36.7 \%$ ) were categorized as $\mathrm{DI}$ and (1 pts.3.3\%) patients could not be categorized. This might be due to excess infusion of normal saline or glucocorticoid concentration in blood. $13.3 \%$ patients developed hyponatraemia SIADH and CSW were equally distributed. Only $2(6.7 \%)$ patients developed combined imbalance.

Table-VII

Distribution of patients by types and pattern of serum sodium imbalance $(n=18)$

\begin{tabular}{lcc}
\hline & Frequency & Percentage \\
\hline Sodium imbalance & 18 & 60.0 \\
Hyponatremia & 4 & 13.3 \\
SIADH & 2 & 6.7 \\
CSW & 2 & 6.7 \\
Hypernatremia & 12 & 40.0 \\
DI & 11 & 36.7 \\
Uncategorized & 1 & 3.3 \\
Combined & 2 & 6.7 \\
SIADH \& DI & 1 & 3.3 \\
CSW \& uncategorized & 1 & 3.3 \\
\hline
\end{tabular}

According to finding of table IX among the 30 patients $17(56.7 \%)$ were finally diagnosed as nonfunctioning pituitary adenomas. $16.7 \%$ patients finally diagnosed as growth hormone secreting pituitary adenoma and also $16.7 \%$ patient diagnosed as craniopharyngioma and other lesions (e.g. visual pathway glioma, tuberculum sellae meningiomas and inconclusive diagnosis) were found only $10 \%$ of patients. Shown in table No. VIII. 
Table-VIII

Distribution of patients by final diagnosis $(n=30)$

\begin{tabular}{lcc}
\hline Final diagnosis & Frequency & Percentage \\
\hline Non functioning adenomas & 17 & 56.7 \\
GH secreting adenomas & 5 & 16.7 \\
Craniopharyngioma & 5 & 16.7 \\
Others & 3 & 10.0 \\
\hline Total & 30 & 100.0 \\
\hline
\end{tabular}

Table X Shows that serum sodium imbalance most frequently occurred at $1^{\text {st }}$ postoperative day. $53.85 \%$ hypernatraemia occurred at 1st postoperative day, $38.46 \%$ hypernatraemia occurred at second day and $7.69 \%$ hyponatraemia occurred at $3^{\text {rd }}$ day. Hyponatraemia occur most frequently at $3^{\text {rd }}$ postoperative day $75 \%$ among the hyponatraemia. Equal frequency was noticed at $1^{\text {st }}$ and $2^{\text {nd }}$ postoperative day.

Table-IX

Distribution of patients by time of onset of postoperative sodium imbalance $(n=18)$

\begin{tabular}{lcc}
\hline Days & $\begin{array}{c}\text { Hyponatremia } \\
(100 \%)\end{array}$ & $\begin{array}{c}\text { Hypernatremia } \\
(100 \%)\end{array}$ \\
\hline Day 1 & $1(22.5)$ & $7(53.85)$ \\
Day 2 & $1(22.5)$ & $5(38.46)$ \\
Day 3 & $3(75)$ & 0 \\
Day 4 & 0 & $1(7.69)$ \\
Day 5 & 0 & 0 \\
Day 6 & 0 & 0 \\
Day 7 & 0 & 0 \\
\hline
\end{tabular}

Fisher's Exact Test was done to measure the level of significance because sample size was in between 20-40 and one quadrant number of patients was $<5$.

The table showed $>30 \mathrm{~mm}$ size group $93.3 \%$ had sodium imbalance and only $26.7 \%$ had sodium imbalance in d" $30 \mathrm{~mm}$ group and there is significant difference of sodium imbalance between large and small size group and p-value is 0.001 .

Table-X

Association of size of lesions with serum sodium imbalance $(n=30)$

\begin{tabular}{lccc}
\hline Size of lesion & \multicolumn{2}{c}{ Sodium imbalance } & p value \\
\cline { 2 - 3 } & present & Absent & \\
\hline$>30 \mathrm{~mm}$ & $14(93.3)$ & $1(6.7)$ & 0.001 \\
$\leq 30 \mathrm{~mm}$ & $4(26.7)$ & $11(73.3)$ & \\
\hline Total & $15(100.0)$ & $15(100.0)$ & \\
\hline
\end{tabular}

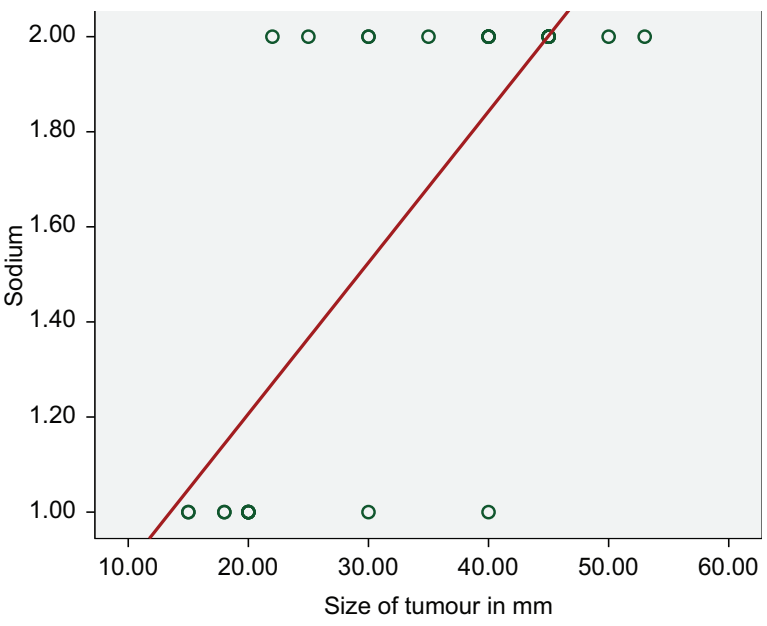

Fig.-1: Correlation of tumour size with serum sodium imbalance $(r=0.776 ; p=0.001)$

$r$ - value 0.776 indicates that the size of the tumour strongly correlates with postoperative sodium imbalance and there is significant association between size of the tumour with sodium imbalance ( $p-0.001)$

Contingency table $\mathrm{XI}$ shows in large size group $(>30 \mathrm{~mm})$ association of sex with postoperative sodium imbalance. As the data were qualitative Fisher's Exact Test was done and there is no association between sex and post operative serum sodium imbalance $(p=1.00) .11$ male showed imbalance but only 7 female showed imbalances.

Table-XI

Association of gender with serum sodium imbalance group 1: Tumour size $>30 \mathrm{~mm}(n=15)$

\begin{tabular}{lccc}
\hline Gender & \multicolumn{2}{c}{ Sodium } & pvalue \\
\cline { 2 - 3 } & Imbalance & Normal & \\
\hline Male & $9(64.3)$ & $1(100.0)$ & 1.000 \\
Female & $5(35.7)$ & $0(0.0)$ & \\
\hline Total & $14(100.0)$ & $1(100.0)$ & \\
\hline
\end{tabular}

Fisher's Exact Test was done to measure the level of significance Test showed that there was no association with age with postoperative sodium imbalance $(p=4.00)$

Table-XI

Association of age with serum sodium imbalance in group :1 (Tumor size $>30 \mathrm{~mm}$ ) $n=15$

\begin{tabular}{lccc}
\hline Age (years) & \multicolumn{2}{c}{ Sodium } & p value \\
\cline { 2 - 3 } & Imbalance & Normal & \\
\hline Median & 32.50 & 50.00 & 0.400 \\
Min - Max & $8.50-70.00$ & $50.00-50.00$ & \\
\hline
\end{tabular}

Mann-Whitney $U$ test was done to measure the level of significant 
The table showed large group (>30 mm) pituitary lesion there is no significant difference of sodium imbalance between type of lesion with postoperative sodium imbalance was independent irrespective of types of the lesion $(p=1.000)$. Table NO. XII.

\section{Table-XII}

Association of types of lesions with serum sodium imbalance in group: 1 (size $>30 \mathrm{~mm}$ ) $n=15$

\begin{tabular}{lccc}
\hline Type of lesion & \multicolumn{2}{c}{ Sodium level } & p value \\
\cline { 2 - 3 } & Imbalance & Normal & \\
\hline Pituitary & $9(64.3)$ & $1(100.0)$ & 1.000 \\
Extra-pituitary & $5(35.7)$ & $0(0.0)$ & \\
\hline Total & $14(100.0)$ & $1(100.0)$ & \\
\hline
\end{tabular}

Fisher's Exact Test was done to measure the level of significance

Contingency table XIII shows association of approach of the surgery with postoperative sodium imbalance in large tumour size. As the data were qualitative, Chi-square test was done and there is no association between approach of the surgery and post operative serum sodium imbalance $(p=0.216)$.

\section{Table-XIII}

Association of approach of the surgery with serum sodium imbalance in group: $1 n=15$

(Tumor size $>30 \mathrm{~mm}$ )

\begin{tabular}{lccc}
\hline \multirow{2}{*}{$\begin{array}{l}\text { ppproach of } \\
\text { the surgery }\end{array}$} & \multicolumn{2}{c}{ Sodium } & p value \\
\cline { 2 - 3 } & Imbalance & Normal & \\
\hline Trans nasal & $4(28.6)$ & $0(0.0)$ & 0.216 \\
microscopic & & & \\
Sublabial & $2(14.3)$ & $0(0.0)$ & \\
$\begin{array}{l}\text { Trans nasal } \\
\text { endoscopic }\end{array}$ & $8(57.1)$ & $1(100.0)$ & \\
\hline Total & $14(100.0)$ & $1(100.0)$ & \\
\hline
\end{tabular}

Chi-square test was done to measure the level of significance

\section{Discussion:}

Seller and suprasellar space occupying lesions are the frequently encountered intracranial lesions now a days. Surgery through transsphenoidal route is the most preferable approach which is frequently performed for excision of these SOL. The lesions are located in a very sensitive area because it is surrounded by hypothalamus, pituitary gland and cavernous sinus which are responsible to maintain various hormonal function and as well as regulation of plasma osmolality and plasma electrolytes. So during and after operation various types of osmolality and electrolytes related complications are noted. Among them serum sodium imbalance is most frequent. As many studies say that it is a independent predictor for postoperative mortality and morbidity.

According to hensen et al., $1999^{13}$ there are some predisposing factors such as patient's age, diagnosis, extension (intrasellar and extrasellar), sex, tumour size (macroadenoma, microadenoma and giant adenoma) may influence the postoperative sodium imbalance. In this study we wanted to prove that large tumour size has an association with postoperative serum sodium imbalance (hyponatraemia or hypernatraemia). Nemerut et al., $2005^{8}$ showed that post operative sodium imbalance occurred due to more aggressive gland and stalk manipulation during resection as well as changes in sellar and suprasellar anatomy in patients with macroadenoma. Jahangiri et al $2013^{14}$ identified that lesion size as a risk factor for postoperative hyponatraemia could reflect the fact that large lesions require manipulation of the pituitary stalk for resection.

Our study was conducted in the department of neurosurgery BSMMU, Dhaka during the period of July 2013 to November 2014 to find out any association between the size of tumour and serum sodium imbalance after transsphenoidal surgery through different routes of the patient having sellar and suprasellar space occupying lesion (SOL).

Final study subject were 30 and age range was 8.5 to 70 years with mean age 32.3 years .The highest incidence was in between $20-40$ years. This did not correspond with the study of Staiger et al., $2013^{1}$ where median patient age was 49 and age range was between 20-78 years.

Staiger et al., $2013^{1}$ found that $52 \%$ female and $48 \%$ male were diagnosed as sellar and suprasellar space occupying lesion. But in our study male predominance was found and male and female ratio was 1.72:1 which bears little consistency with the finding of other investigator.

Common clinical picture of this type of patients due to mass effect of expanding tumor impinging on neighbor structures: visual defects (from minimal visual field defect to typical hemianopsia to aurosys), headache, and symptoms of hyper and hypopituitarism ${ }^{15}$. In our study most frequent clinical feature were head ache and visual disturbance $96 \%$ 
and $100 \%$ respectively which consisted with the above mentioned study and Jho et al., $2012^{16}$ also gave the same statement.

In our study nonfunctioning pituitary tumours were the most frequently encountered lesions in sellar and suprasellar region (about $56.7 \%$ of the total lesions). Pituitary adenomas account for about $90 \%$ of lesions of the sellar and parasellar region according to different large surgical series, like the German Registry of pituitary tumours ${ }^{17}$. And according to Stiger et al., $2013^{1} 56 \%$ of the operated lesions were non functioning pituitary adenomas. Our study findings almost correspond with the finding.

According Juraschka et al.,2014 ${ }^{18}$ explain the extend of resection near-total mean when more e" $90 \%$ of the tumours are resected, subtotal $(70 \%-89.9 \%)$ and partial $(<70 \%)$. In our study near total removal endoscopic was done on $63.3 \%$ of patients. Subtotal removal was done on $26.7 \%$ of patients. $10 \%$ of patients lesions were removed partially.

According to staiger et al., $2013^{1}$ incidence of development of serum sodium imbalance in both male and female is equal and the ratio is 1:1:0.9. Previous study also found no impact of sex on the incidence of postoperative DI or hyponatremia ${ }^{13}$ (Hensen et al., 1999). In our study there was no association between sex and postoperative sodium imbalance $(p=0.757)$ which corresponds with the study of the above mentioned investigator.

$60 \%$ of the patients in our study developed post operative serum sodium imbalance after transsphenoidal surgery. Among them $40 \%$ of the patients developed hypernatraemia, $13.3 \%$ of the patient developed hyponatraemia and only $6.7 \%$ patient developed combined imbalance Hypernatraemia is more common than hyponatraemia after transsphenoidal surgery. Some study showed that $35 \%$ patients developed hypernatremia ( $\mathrm{Na}>145$ $\mathrm{mmol} / \mathrm{L}$ ) with peak sodium levels at a median of 2 days (mean 2.3 days) following surgery and 18\% patients developed hyponatraemia ( $\mathrm{Na}<135 \mathrm{mmol} / \mathrm{L})$ with sodium levels at a median of 6 days (mean 6.4 days) postoperative ${ }^{1}$. Our study result also corresponds with this study.

Hyponatremia as a complication of general elective surgery occurs that within 48 hours ${ }^{19}$. Transient begins with an abrupt onset of polyuria within $24-48 \mathrm{~h}$ of surgery and gradually resolves over $3-5$ day period $^{12}$. In our study the peak incidence of hyponatraemia occurred on $3^{\text {rd }}$ post operative day and hypernatraemia occurred at $1^{\text {st }}$ postoperative day which consistent partially with the study of Staiger et al., $2013^{1}$; they found peak sodium level at $2^{\text {nd }}$ (mean2.3days) day but hyponatraemia developed on day 6 (mean6.4 days).

Approximately $50 \%$ of patients operated for pituitary adenoma developed polyuria or mild hyponatraemia, mostly transient. It cannot be ruled out that some immediate hyponatraemia observed in our patients might be due to extensive neurosurgical exploration, leading to immediate release of AVP from the posterior pituitary. Symptomatic hyponatraemia occurs on an average about 8 days after surgery with arrange of 413 days $^{13}$.

The pathophysiology of hyponatremia after transsphenoidal surgery is complex. It is initiated by pituitary damage that produces AVP secretion and dysfunctional osmoregulation in most surgically treated patients ${ }^{20}$.

Tumour size was associated with an increased incidence of sodium imbalance in non functioning pituitary adenomas. Large tumours cause significantly more sodium disturbance. The incidence of a plasma sodium disturbance was $61 \%$ in the group with large tumours and $43 \%$ in small tumour group. This supports the findings of an earlier study, which stated that patients with macroadenomas are more prone to develop delayed hyponatraemia than patients with small tumours. This contrasts with the study of Hensen et al. suggesting that tumour size was of significance $(p=0.015)$ for the development of postoperative hyponatraemia ${ }^{1}$.

Patients with macroadenoma are somewhat more prone to develop delayed hyponatraemia than patients with small tumours ${ }^{13}$ (Hensen et al., 1999). Some authors have shown that $\mathrm{DI}$ is more common after the resection of macroadenoma. The circumstance is likely to be caused by the more aggressive gland and stalk manipulation required during resection as well as changes in sellar and suprasellar anatomy in patients with macroadenoma ${ }^{8}$ (Nemergut et al., 2005). Our study $60 \%$ patients developed postoperative sodium imbalance, among them $46.66 \%$ imbalance occurred in large group (>30mm) and only $13.33 \%$ sodium imbalance occurred in small group (d" $30 \mathrm{~mm}$ ) group. There was significant difference of sodium imbalance between large and small size group and p- 
value was 0.001 . According to Spearmen correlation test in our study showed $r$-value 0.776 which indicates that the size of the tumour strongly correlates with postoperative sodium imbalance and there is significant association between size of the tumour with sodium imbalance. That indicates large tumour produces sodium imbalance in postoperative period. The result is consistent with previous study.

The analysis of the tumour size in our study showed that tumour size increases with age. This implies that in older patients more time passes until symptoms occur which result in presenting to a doctor who makes the diagnosis. However comparing the size of the tumour with the age of the patient and the occurrence of sodium disturbance, the elder group of patients showed a similar incidence of sodium imbalance with small as well as with large tumours (52\% small, $54 \%$ large).

Trans-sphenoidal surgery, now a days, include more than $95 \%$ of the surgical indications in the sellar area and approximately $96 \%$ of all pituitary adenomas ${ }^{16}$.

Craniopharyngioma or an RCC appear to have an increased risk of transient $D I$. The incidence is less in comparison of other lesions ${ }^{8}$. Lesions such as craniopharyngiomas that typically arise closer to the pituitary stalk theoretically increasing the risk for postoperative hyponatraemia. However, Jahangiri et al., $2013^{14}$ failed to identify pathology as a risk factor for postoperative hyponatraemia. Our study support the above mentioned statement which found no significant association between types of the lesions with postoperative sodium imbalance $(p=0.43)$.

\section{Conclusion:}

Post operative serum sodium imbalance after transsphenoidal surgery is a burning issue for the neurosurgeon now a days because some time it is an independent predictor for the mortality of the patient. Early prediction of these types of very notorious complication is helpful for preoperative and post operative management of the patient. The size of the lesion is one of the most significant markers. As well as an strong association between size of the tumour with post operative sodium imbalance was found. This will help us in perioperative management of the patients, and reduces complication related mortality and morbidity after the transsphenoidal surgery.

\section{References:}

1. Staiger RD, Sarnthein J, Wiesli P, Schmid C \& Bernays RL. Prognostic factors for impaired plasma sodium homeostasis after transsphenoidal surgery. $\mathrm{Br} J$ Neurosurg, 2013; 27: 63-8.

2. Strachan MWJ \& Walker BR. Endocrine disease. In: COLLEDGE, N. R., WALKER, B. R. \& RALSTON, S. H. (eds.) Davidson's Principles and Practice of Medicine. New York: Churchill Livingstone.2010.

3. Attanasio R, Cozzi R, Lasio G. \& Barbo R. Diagnostic Evaluation of the Lesions of the Sellar and Parasellar Region. In: SIGNORELLI, F. (ed.) Explicative Cases of Controversial Issues in Neurosurgery. Croatia. 2012.

4. Famini P., Maya MM \& Melmed S. Pituitary magnetic resonance imaging for sellar and parasellar masses: tenyear experience in 2598 patients. J Clin Endocrinol Metab, 2011; 96: 1633-41.

5. Ganong FW. Central regulation of visceral function. In: GANONG, F. W. (ed.) Review of medical physiology. McGraw-Hill. 2003.

6. Yasargil MG, Curcic M, Kis M., Siegenthaler G, Teddy PJ \& Roth P. Total removal of craniopharyngiomas. Approaches and long-term results in 144 patients. J Neurosurg, 1990;73: 3-11.

7. Nomikos P, Ladar C, Fahlbusch R \& Buchfelder M. Impact of primary surgery on pituitary function in patients with non-functioning pituitary adenomas - a study on 721 patients. Acta Neurochir (Wien), 2004; 146: 27-35.

8. Nemergut EC, Zuo Z, Jane JA JR \& Laws ER JR. Predictors of diabetes insipidus after transsphenoidal surgery: a review of 881 patients. J Neurosurg, 2005; 103: 448-54.

9. Sigounas DG, Sharpless JL, Cheng DM, Johnson TG, Senior BA \& Ewend MG. Predictors and incidence of central diabetes insipidus after endoscopic pituitary surgery. Neurosurgery, 2008; 62:71-8; discussion 78-9.

10. Loh JA \& Verbalis JG. Disorders of water and salt metabolism associated with pituitary disease. Endocrinol Metab Clin North Am, 2008; 37: 213-34, x.

11. Zada G, Liu CY, Fishback D., Singer PA \& Weiss MH. Recognition and management of delayed hyponatremia following transsphenoidal pituitary surgery. J Neurosurg, 2007; 106:66-71.

12. Schreckinger M, Szerlip N \& Mittal S. Diabetes insipidus following resection of pituitary tumors. Clin Neurol Neurosurg, 2013; 115:121-6.

13. Hensen J, Henig A, Fahlbusch R, Meyer M, Boehnert M \& Buchfelder M. Prevalence, predictors and patterns of postoperative polyuria and hyponatraemia in the immediate course after transsphenoidal surgery for pituitary adenomas. Clin Endocrinol (Oxf), 1999; 50: 431-9.

14. Jahangiri A, Wagner J, Tran MT, Miller LM, Tom MW, Kunwar S, Blevins L JR. \& Aghi MK. Factors predicting postoperative hyponatremia and efficacy of hyponatremia management strategies after more than 1000 pituitary operations. J Neurosurg, 2013; 119: 1478-83. 
15. Meij BP, Lopes M B, Ellegala DB, Alden TD \& Laws ER JR. The long-term significance of microscopic dural invasion in 354 patients with pituitary adenomas treated with transsphenoidal surgery. J Neurosurg, 2002; 96:195-208.

16. Jho DH \& JHO H-D. Endoscopic Endonasal Pituitary and Skull Base Surgery. In: QUIÑONES-HINOJOSA, A. (ed.) Schmidek \& Sweet Operative Neurosurgical Techniques. Sixth ed. Philadelphia: Elsevier,2012.

17. Freda PU \& Post KD. Differential diagnosis of sellar masses. Endocrinol Metab Clin North Am, 1999; 28:81-117, vi.

18. Juraschka K, Khan OH, Godoy BL, Monsalves E, Kilian A, Krischek B, Ghare A, Vescan A, Gentili F \& Zadeh G.
Endoscopic endonasal transsphenoidal approach to large and giant pituitary adenomas: institutional experience and predictors of extent of resection. J Neurosurg, 2014; 121 : 75-83.

19. Taylor SL, Tyrrel JB \& Wilson CB. Delayed onset of hyponatremia after transsphenoidal surgery for pituitary adenomas. Neurosurgery, 1995; 37: 649-53; discussion 653-4.

20. Olson BR, Gumowski J, Rubino D \& Oldfield EH. Pathophysiology of hyponatremia after transsphenoidal pituitary surgery. J Neurosurg, 1997; 87: 499-507. 